\title{
Hydrologic Connectivity for Highway Runoff Analysis at Watershed Scale
}

\author{
Zhaochun Meng, Jy S. Wu and Craig J. Allan
}

Roadway networks represent a unique type of drainage area, encompassing hundreds of miles (kilometers) of linear stretches of paved surfaces that frequently cross watershed boundaries, streams and sensitive water bodies. Runoff from this land use category contains a variety of pollutants such as sediments, trace metals, hydrocarbons and nutrients. As mandated by the United States Clean Water Act and other environmental regulations, state transportation agencies are required to implement control measures to comply with the allocation of allowable pollutant loads that are established by the total maximum daily loads (TMDL) requirements. Adapting a technically sound methodology for watershed modeling is the key to providing reliable estimates of pollutant loads from highway runoff.

Various modeling tools are available. Regression models are based on analyzing field monitoring data to determine the relationships between causal and explanatory variables (Chui et al., 1982; Kerri et al., 1985; Schueler, 1987; Driscoll et al., 1990; Driver and Tasker, 1990; Irish et al., 1998; Wu et al., 1998; Kayhanian et al., 2007; Wu and Allan, 2010). Simulation models include the principal mechanisms of generation, transport and dispersal of stormwater runoff and the associated pollutants, as illustrated by the USEPA's Storm Water Management Model.

Existing methodologies used for estimating pollutant loadings from highway runoff can be subject to the following limitations:

1. Regression models derived from site specific monitoring data

Meng, Z., J.S. Wu and C.J. Allan. 2013. "Hydrologic Connectivity for Highway Runoff Analysis at Watershed Scale." Journal of Water Management Modeling R246-02. doi: 10.14796/JWMM.R246-02.

(C) CHI 2013 www.chijournal.org ISSN: 2292-6062 (Formerly in Pragmatic Modeling of Urban Water Systems. ISBN: 978-0-9808853-8-5) 
may not be appropriate for watershed assessment of the highway network;

2. Most studies place emphasis on the impervious road surface, rather than the entire rights-of-way (ROW) land use and roadside vegetated pervious areas;

3. Water quality data of highway runoff are not typically employed for calibrating TMDL models because calibration is based on the observed in-stream data, from which it may not be possible to segregate the sources and the contributing runoff from different land uses;

4. Most studies ignore the significance of flow pathways connecting highway drainage to receiving streams; and

5. Uncertainty associated with propagation errors is not considered by TMDL models.

To address some of these shortcomings (namely 2, 3 and 4), this chapter presents a computational algorithm for determining the hydrologic connectivity between roadway ROWs and receiving streams. The methodology is further extended to quantify the relative proportion of runoff and pollutant loads originating from roadway ROWs discharging into receiving streams or ditches. The concept of probabilistic volume-to-breakthrough (Hairsine et al., 2002) is revised and implemented on a GIS platform to identify different flow pathways, allowing subsequent computational procedures to be implemented on Microsoft Excel spreadsheets. The approach also considers the uncertainty associated with propagation errors that have not been attempted by previous TMDL models.

\subsection{Methodology}

The probabilistic volume-to-breakthrough (PVbt) concept was described by Hairsine et al. (2002) as a way to obtain runoff volume that is required to flow through its flow pathway and produce appreciable discharges at the downslope boundary. This breakthrough volume accounts for water losses due to infiltration through overland flow and depression storage, and in transit between the upper and lower boundaries along the flow pathway. Flow paths may include direct connection between road segments and stream crossings, incised flow between road drainage outlets and the stream, and diffuse overland flow on road surfaces across slopes (Wemple et al., 1996; Croke et al., 1999; Hairsine et al., 2002; Bracken et al., 2004; Eastaugh et al., 2008).

The application of PVbt to determine storm runoff and pollutant discharges from forested roads was reported by Australian researchers (Lane et al., 2006; Takken et al., 2008; Eastaugh et al., 2008; Thompson et al., 2009). 
Their results indicate that the variance of road-to-stream connectivity depends on factors such as watershed topography, road placement, drainage spacing along the roadway, and road and drainage density. Eastaugh et al. (2008) provided a procedure to quantify the hydrologic connectivity for individual road segments and the road network as a whole by explicitly considering both the uncertainty of connectivity in terms of confidence limits, and the potential impacts of road segments that may or may not be hydrologically connected to the stream network.

According to Hairsine et al. (2002), the mean volume of overland flow required for a runoff plume to reach a standard distance of $5 \mathrm{~m}$ from the road edge $\left(V_{b t 5}\right)$ and its variance $\left(\sigma_{V b t 5}{ }^{2}\right)$ can be employed to predict the mean length of the overland flow plume $\left(l_{\text {pred }}\right)$ and its variance $\left(\sigma_{l}^{2}\right)$ for any given discharge $\left(V_{\text {out }}\right)$ at the road edge:

$$
\begin{aligned}
& l_{\text {pred }}=5 V_{\text {out }} / V_{b t 5} \\
& \sigma_{l}^{2}=\left[5 \sigma_{\text {Vbt5 }} V_{\text {out }} / V_{b t 5}{ }^{2}\right]^{2}
\end{aligned}
$$

The mean volume of surface flow at a distance $(x)$ downslope of the road edge $\left(V_{x}\right)$ and its variance $\left(\sigma_{V x}^{2}\right)$ are given as:

$$
\begin{gathered}
V_{x}=V_{o u t}-V_{b t 5} * x / 5 \\
{\sigma_{V x}}^{2}=\left[\sigma_{V b t 5} * x / 5\right]^{2}
\end{gathered}
$$

The road-to-stream connectivity $(\psi)$ can be defined as the ratio of runoff volume reaching the stream network $\left(V_{X}\right)$ to the runoff volume originating from the roadway ROW $\left(V_{\text {out }}\right)$ :

$$
\psi=V_{X} / V_{\text {out }}
$$

where the subscript ${ }_{X}$ indicates the actual length of the diffuse pathway starting from the road edge to the receiving stream or channel.

In Equation 2.5, $V_{\text {out }}$ can be estimated using appropriate hydrologic methods (e.g. Schueler, 1987) or with the aid of field monitoring. Our approach includes the entire roadway ROWs and, therefore, is different from the work by Eastaugh et al. (2008). Three different cases can be used to illustrate the application of the road-to-stream connectivity as given by Equation 2.5.

\section{Case A: $\psi=1$ for directly connected road segments with streams}

In this case, road segments are directly connected to a stream network via concentrated flow such as flow through pipes, ditches or channels, or via overland flow travelling a short distance to a stream crossing. The road-to-stream connectivity is assumed to be unity because of minimal losses of runoff in pipe 
flow, along overland slopes, or at the cut-and-fill roadway or stream crossing.

Case B: $0<\psi<1$ for diffusely connected road segments with streams

In this case, roadway runoff travels over pervious areas as overland flow prior to discharging to crossing streams. The mean runoff volume reaching a stream will be a fraction of $V_{\text {out }}$ (i.e. $\psi V_{\text {out }}$ ).

Case $C: \psi=0$ for diffusely connected road segments

This is the case when the predicted length of a flow plume is equal to or less than the actual length $(X)$ of the diffuse pathway. There will be no mean runoff volume reaching a stream.

Whether or not the flow is expected to reach a stream, the absolute and relative uncertainties associated with error propagation are, respectively:

$$
\begin{aligned}
& \varepsilon_{x}= \pm z \sigma_{V x} \\
& \varepsilon_{x}^{\prime}= \pm z \sigma_{V x} / V_{x}= \pm z \sigma_{V x} /\left(V_{\text {out }}-V_{b t 5} * x / 5\right)
\end{aligned}
$$

where $z$ is associated with a desired level of confidence.

For instance, the $z$ value of 1.645 yields a 95\% confidence interval about the mean. The absolute uncertainty would attain its maximum value, $\varepsilon_{X}= \pm \mathrm{z} \sigma_{V X}$ when $V_{X}=0$ (i.e. $V_{\text {out }}=V_{b t 5} * X / 5$ ) and will remain unchanged even if $V_{\text {out }}$ increases. However, the relative uncertainty will be reduced as $V_{\text {out }}$ increases. Based on Equations 2.1 to 2.6, Meng (2012) derived the runoff volume originating from a single road segment and reaching the stream network by incorporating uncertainty considerations as follows:

$$
\begin{gathered}
V_{X}=V_{\text {out }} \text { for directly connected segment when } \psi=1 ; \\
V_{X}=\left(\begin{array}{l}
\left.V_{\text {out }}-V_{\text {bt }} * X / 5\right)+\varepsilon_{X} \text { for diffusely connected segment } \\
\text { when } 0<\psi<1 ;
\end{array}\right. \\
\begin{aligned}
V_{X}=0+\varepsilon_{X} \text { for diffused connected segment when } \psi=0 \text { with } \\
\quad l_{\text {pred }}=X\left(\text { i.e. } V_{\text {out }}=V_{b t 5} * X / 5\right) \text {; and }
\end{aligned} \\
\begin{array}{c}
V_{X}=0+ \\
\quad\left(2 \varepsilon_{\text {lpred }}-\varepsilon_{X}\right) \text { for diffusely connected segment when } \psi \\
\quad 0 \text { with } 0.5 X<l_{\text {pred }}<X . \text { That is, the predicted flow } \\
\text { plume relative to } V_{\text {out }} \text { lies between } 0.5 X \text { and } X .
\end{array}
\end{gathered}
$$

The predicted total runoff from the entire road network reaching the stream network can then be determined as the sum of the predicted runoff from each road segment, based on different flow pathways as explained above. The uncertainty associated with total runoff can also be estimated in terms of error propagation theories. As such, stormwater runoff from the roadway land use of the entire road network can be assessed to inform transportation agencies for implementing stormwater management and TMDL requirements within their jurisdictions. 
The computational procedures for determining the overall road-tostream hydrologic connectivity are (see Figure 2.1):

1. Delineate catchment areas for highway stormwater and measurement of flow pathways by performing terrain pre-processing and field survey;

2. Apply road characteristic attributes of the existing road centerline GIS shape file to determine drainage area and impervious percentage;

3. Estimate runoff volumes originating from roadway land use of each road segment;

4. Determine $V_{b t 5}$ through field experiments, hydrologic methods, or from literature values with appropriate adjustment to fit local climatic and hydrogeological conditions; and

5. Calculate road runoff reaching streams and its associated uncertainty.

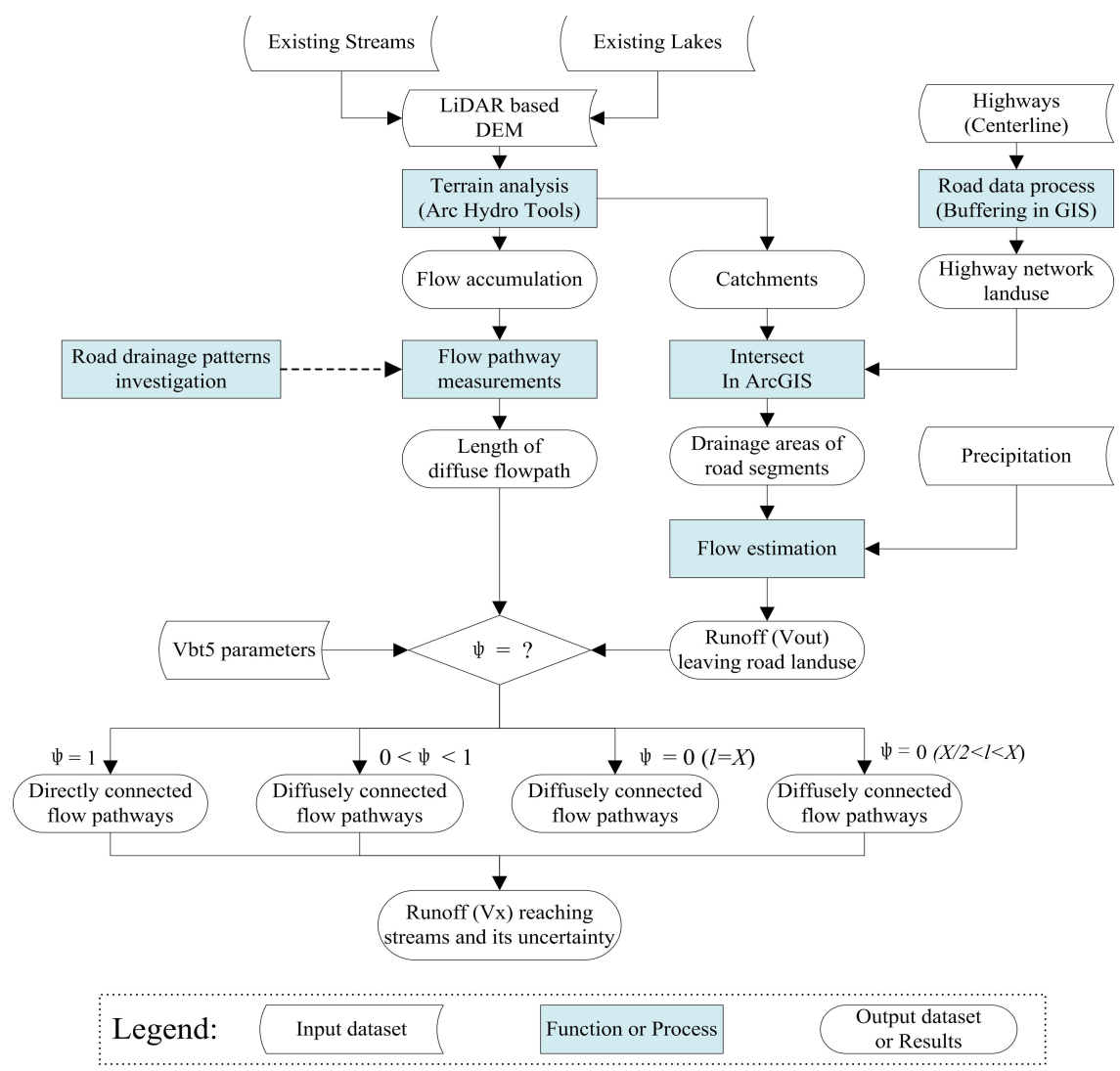

Figure 2.1 GIS implementation and runoff calculations. 


\subsection{Results and Discussion}

Road-to-stream hydrologic analysis was performed on the road network within the Lake Orange watershed in Orange County, North Carolina (Figure 2.2). This $26.7 \mathrm{mi}^{2}$ (17 114 acre, $69.57 \mathrm{~km}^{2}$ ) rural watershed includes 231 acre (93.9 ha) state owned roadway land use with $49.2 \%$ impervious pavement. The total road length is approximately $47 \mathrm{mi}(75.6 \mathrm{~km})$ and the road density is $1.75 \mathrm{mi} / \mathrm{mi}^{2}\left(1.01 \mathrm{~km} / \mathrm{km}^{2}\right)$.

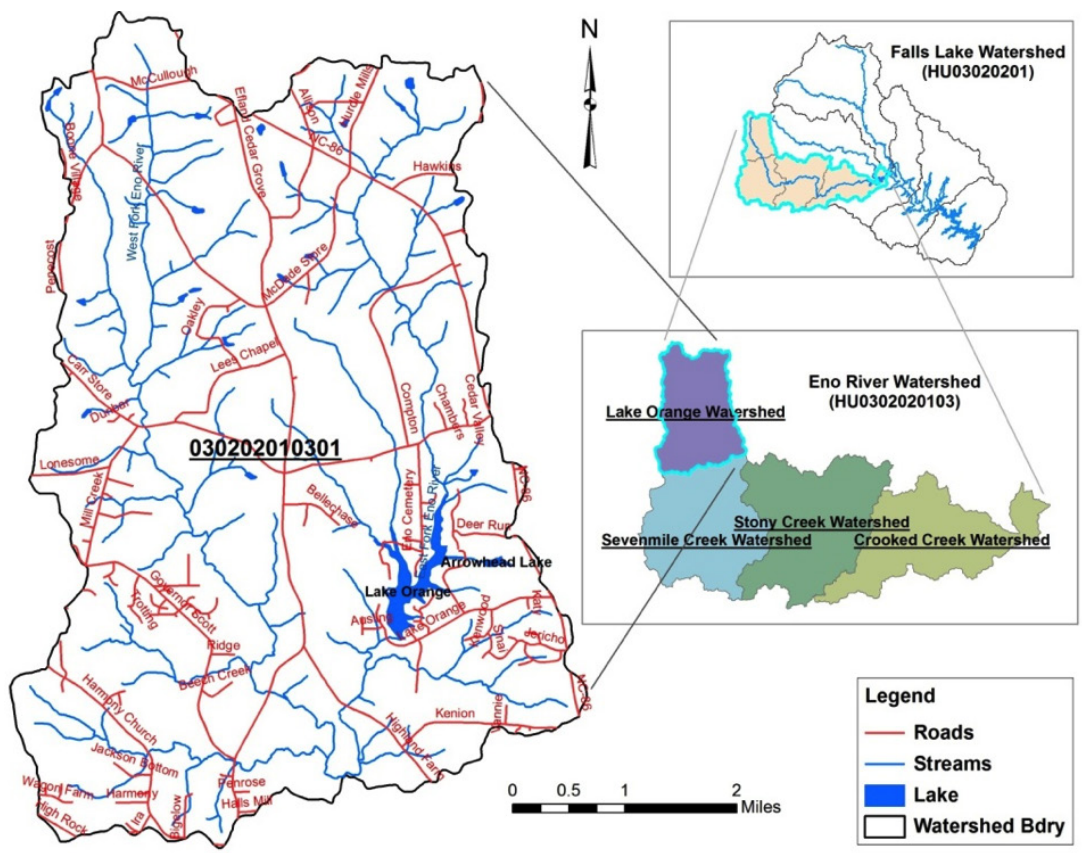

Figure 2.2 The Lake Orange watershed.

Data input include daily precipitation (2004-2007), drainage area and imperviousness coverage of individual road segments, drainage pattern information and lengths of overland flow pathways, and $V_{b t 5}$ values. Relevant data was retrieved from the Orange County high resolution Lidar based digital elevation model (DEM) with a grid spacing of $20 \mathrm{ft} \times 20 \mathrm{ft}(6.1 \mathrm{~m} \times 6.1 \mathrm{~m})$; the HU0302 high resolution watershed boundary dataset and National Hydrography Dataset (NHD, also known as NHDinGEO), containing rivers and streams (NHD flow line), lakes and big ponds (NHD waterbody), and twelve digit watershed boundary data; and road characteristics ArcGIS layer (road centerline shape file). 
Figure 2.3 displays the overall road generated runoff and runoff delivered to streams as affected by daily precipitation. Based on the impervious fraction of road ROWs and the linear relationship between precipitation and the road-generated runoff, a 1 in. $(25.4 \mathrm{~mm})$ rainfall would produce $0.37 \mathrm{in}$. $(9.4 \mathrm{~mm})$ road runoff. A portion of this runoff $(0.14 \mathrm{in} ., 3.6 \mathrm{~mm})$ is lost during delivery with only $0.23 \mathrm{in}$. $(5.8 \mathrm{~mm})$ reaching streams. The runoff reaching streams would have been estimated at $0.37 \mathrm{in}$. $(9.4 \mathrm{~mm})$ if hydrologic connectivity was not used for runoff calculations. The ratio of the delivered runoff to precipitation will increase as the rainfall increases, varying from 0.084 to 0.315 during the period 2004-2007.

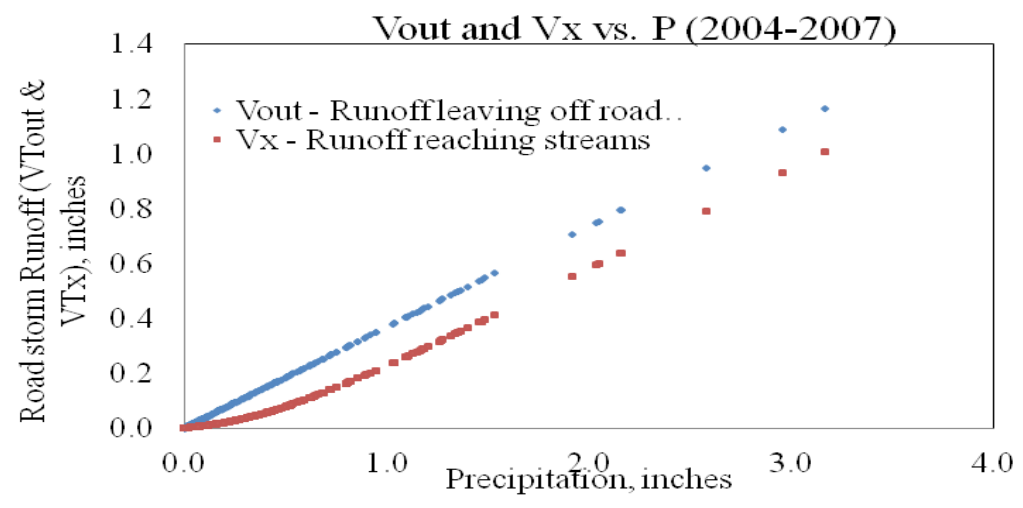

Figure 2.3 Relationship between precipitation and roadway runoff.

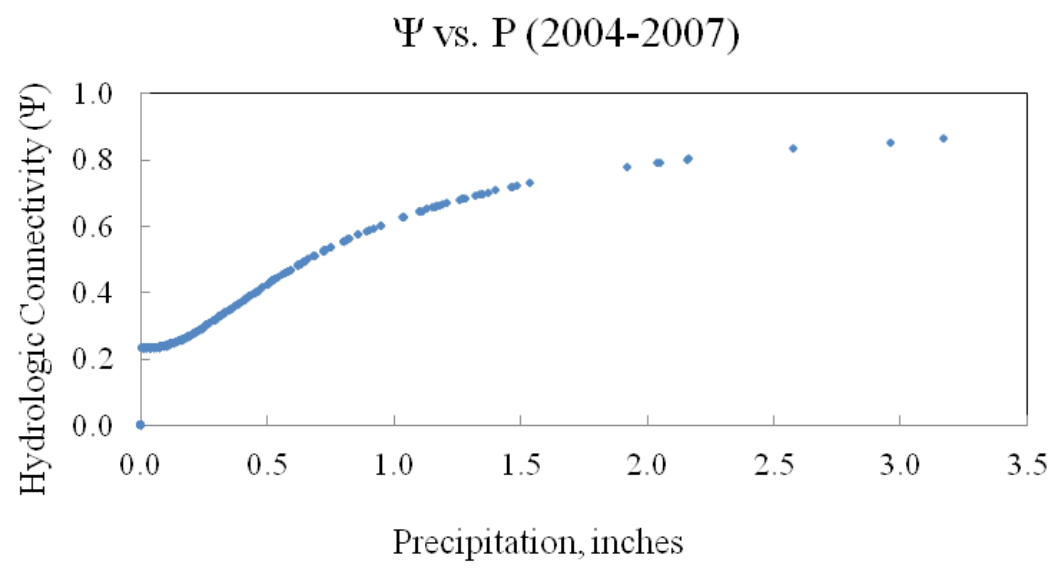

Figure 2.4 Influence of precipitation on hydrologic connectivity. 
Figure 2.4 above shows that the road-to-stream hydrologic connectivity is dependent on rainfall. The connectivity will increase as rainfall increases. The overall hydrologic connectivity of the road network to the stream network in the Lake Orange watershed was found to be $0.32 \pm 0.14$, ranging from 0.23 to 0.86 .

\subsection{Conclusion}

This research has developed a computational algorithm for determining the hydrologic connectivity between roadway ROWs and receiving streams, and the stormwater runoff reaching the stream network from the entire roadway land use at watershed scale. The algorithm takes into consideration the uncertainty of runoff volumes reaching the receiving stream as it is affected by the amount of runoff volumes originating from roadway drainage. Research will be continued to integrate this hydrologic algorithm to a water quality model. The final product will include the hydrologic and water quality modules for implementing TMDL calculations for highway runoff.

\section{References}

Bracken, L. J., Croke, J. and Kirkby, M. (2004). "Connectivity in geomorphology: definition and evaluation." Geophysical Research Abstracts, 6, 04039.

Chui, T. W., Mar, B. W. and Horner, R. R. (1982). "Pollutant loading model for highway runoff." Journal of Environmental Engineering, 108 (6), 1193-1210.

Croke, J. C., Hairsine, P. B. and Fogarty, P. (1999). "Runoff generation and redistribution in logged eucalyptus forests, Southeastern Australia.” Journal of Hydrology, 101, $55-77$.

Driscoll, E. D., Shelley, P. E. and Strecker, E. W. (1990). "Pollutant loadings and impacts from highway stormwater runoff, volume III: analytical investigation and research report.” Federal Highway Administration, Publication No. FHWA-RD-88-008. 160 p.

Driver, N. E. and Tasker, G. D. (1990). "Techniques for estimation of storm-runoff loads, volumes, and selected constituent concentrations in urban watersheds in the United States." U.S. Geological Survey, Washington, DC.

Eastaugh, C. S., Rustomji, P. K. and Hairsine, P. B. (2008). "Quantifying the altered hydrologic connectivity of forest roads resulting from decommissioning and relocation." Hydrological Processes, 22,2438-2448, doi: 10.1002/hyp.6836.

Hairsine, P. B., Croke, J. C., Matthews, H., Fogarty, P. and Mockler, S. P. (2002). "Modelling plumes of overland flow from roads and logging tracks". Hydrological Processes, 16, 2311-2327, doi: 10D1002/hyp.1002.

Irish, L. B., Barrett, M. E., Malina, J. F. and Charbeneau, R. J. (1998). "Use of regression models for analyzing highway stormwater loads." Journal of Environmental Engineering, 124 (10), 987-993. 
Kayhanian, M., Suverkropp, C., Ruby, A. and Tsay, K. (2007). "Characterization and prediction of highway runoff constituent event mean concentration." Journal of Environmental Management, 85, 279-295.

Kerri, K. D., Racin, J. A. and Howell, R. B. (1985). "Forecasting pollutant loads from highway runoff." Transportation Research Record, 1017, 39-46.

Lane, P. N. J., Hairsine, P. B., Croke, J. C. and Takken, I. (2006). "Quantifying diffuse pathways for overland flow between the roads and streams of the Mountain Ash Forests of Central Victoria Australia." Hydrological Process, 20, 1875-1884.

Meng, Z. (2012). "Watershed-scale modeling methodologies for estimating highway stormwater TMDLs." Ph.D. Dissertation. Infrastructure and Environmental Systems Interdisciplinary Program and Department of Civil and Environmental Engineering, University of North Carolina at Charlotte, Charlotte, NC.

Schueler, T. (1987). "Controlling urban runoff: a practical manual for planning and designing urban BMPs.” Metropolitan Washington Council of Governments. Washington, DC

Takken, I., Croke, J. C. and Lane, P. (2008). "A methodology to assess the delivery of road runoff in forestry environments." Hydrological Processes, 22(2), 254-264.

Thompson, C., Newham, L. T. H., Croke, B., Jakeman, A.,and Takken, I. (2009). "Road runoff and sediment connectivity assessment tool: ROADCAT." http://fennerschoolresearch.anu.edu.au/roads_dss/publications/pdfs/model_specification_b5.pdf

Wemple, B. C., Jones, J. A. and Grant, G. E. (1996). "Channel network extension by logging roads in two basins, western cascades, Oregon." Water Resources Bulletinm 23(6):1195-1207.

Wu, J. S. and Allan, C. J. (2010). "Unified methodology for site-characterization and sampling of highway runoff.” Front. Environ. Sci. Engin. China, 4(1), 47-58.

Wu, J. S., Allan, C. J., Saunders, W. L. and Evett, J. B. (1998). “Characterization and pollutant loading estimation for highway runoff." Journal of Environmental Engineering, 124 (7), 584-592. 
